\title{
Removal of colour from alkali extracted wastewater of Pulp and paper mill using fly ash as adsorbent
}

\begin{abstract}
Anju Malik
Department of Energy and Environmental Sciences, Chaudhary Devi Lal University, Sirsa (Haryana), India

Shaveta Kakkar*

Avantha Centre for Industrial Research and Development, Paper Mill Campus, Yamuna Nagar (Haryana), India

Sanjeev Gupta

Aditya Birla Water Application and product development Centre, Grasim Industries Limited, Vilayat Industrial Estate, Bharuch (Gujarat), India

*Corresponding author. E-mail: shaveta27@gmail.com

Abstract

The study aims to explore the beneficial use of fly ash and its effectiveness as low cost adsorbent for wastewater treatment of Pulp and paper industry. A comparative study was also carried out for the better colour reduction of industrial effluent using fly ash and commercial activated carbon. Batch mode adsorption experiments were carried out to optimize the different experimental conditions like adsorbent dose, contact time, rotation per minute (RPM) and $\mathrm{pH}$. The treatment showed that the removal efficiency of colour increased to $86 \%$ with the increase in adsorbent dose $(0.5-10 \mathrm{~g})$, time (30-240 min), RPM $(50-150)$ and $\mathrm{pH}(4-12)$ of pulp and paper industry wastewater. The removal efficiency of activated carbon was found to be $100 \%$ using $1 \mathrm{~g}$ adsorbent dose of commercial grade activated carbon. The Scan Electron Microscope (SEM) results of the fly ash showed that the particles looked like somewhat spherical large particles. It was concluded that though the activated carbon was very efficient adsorbent in comparison to fly ash, the better solution for disposal of solid waste such as fly ash can be good a substitute as the adsorbent for the colour reduction of the paper mill wastewater.
\end{abstract}

Keywords: Adsorbent, Activated carbon, Colour, Fly ash, Pulp and paper, Wastewater

\section{INTRODUCTION}

Water of acceptable quality is essential for agricultural, industrial, domestic and commercial uses but water of high quality is essential for human life (Renge, 2012). Pulp and paper ( $P$ and $P$ ) industry is one of the most polluting industries, as identified and categorized by Central Pollution control Board (CPCB), India. Controversially, the Pulp and paper industry as it stands now, is one of the largest major contributor of pollution load in our aquatic environment. The paper industry is the largest industry in India (Medhi et al., 2011; Shivnarayan, 2015) and it ranks 20th paper producing country among the world (Malaviya et al. 2007). During papermaking a huge quantity of water is being utilized but a large fraction of this water is finally generated as liquid waste. Pulping and bleaching processes of paper manufacturing generate huge amount of solid as well as liquid waste. Integrated and non integrated pulp and paper mills in India generate near about $60-125 \mathrm{~m}^{3}$ and $10-50 \mathrm{~m}^{3}$ of

\section{Article Info}

DOI:10.31018/jans.v10i4.1836

Received: July 23, 2018

Revised: November 27, 2018

Accepted: November 30, 2018

\section{How to Cite}

Malik, A. et al. (2018). Removal of colour from alkali extracted wastewater of Pulp and paper mill using fly ash as adsorbent. Journal of Applied and Natural Science, 10(4): 1318-1324 
colour to water are not directly toxic to aquatic species it increase the biological oxygen demand results deplete the level of dissolved oxygen which is necessary for survival of aquatic life. Lignin and its derivatives are hard to degrade due to strong bonding in its molecular structure, especially biphenyl-type carbon to carbon linkages (Karrasch et al. 2006). So, effluent treatment for removal of colour is essential to protect the environment as well as aquatic life.

Different types of technologies are used for the treatment of wastewater like sedimentation, dissolved air floatation and filtration, chemical precipitation, coagulation, activated sludge systems and anaerobic treatments (Amuda and Ibrahim, 2006). All these methods have high operational maintenance cost, complicating, time consuming and also itsrecovery methods are very expensive. Removal of colour by conventional chemicals and biological methods is not effective. Chemical and physical treatment using adsorption technique is preferable for the removal of colour. Adsorption is a reliable technique that achieves rapid results (Igwe et al., 2013; De 2008). Activated carbon is widely used for the removal of colour (Chakradhar and Shrivastava 2004; Popuri et al., 2016), chemical oxygen demand (COD) (Hami et al. 2007), biological oxygen demand (BOD) (Devi and Dahiya, 2008) and heavy metals (Hamadi et al., 2001) from effluent due to its effectiveness and versatility.

Utilization of coal is increasing day by day due to high boom in industrial growth and high energy demand which produces large quantity of waste named as fly ash. The nature of fly ash is completely dependent on its geological origin and combustion conditions. Currently more than 90 million tons of fly ash is being generated annually in India, with 65000 aceres of land being occupied by ash ponds(Varma et al. 2013). In India, most of the utility thermal power and sub-bituminous coal with high ash content $30-50 \%$ resulting in the huge quantity of fly ash(Dimple and Mehta 2014). A very small portion of fly ash is used and rest of it is dumped, which causes great threat to the environment. Disposal of this is a major global issue and its effective handling, utilization, disposal is major challenge.

Electrostatic precipitators are used to collect these particles. The fly ash particles are very light and fine so do not settle easily and remain suspended in air. Its composition depends on which type of coal is used in thermal power plant. Fly ash has great strength to act as a good adsorbent due to presence of chemical component like silica 35$70 \%$, alumina $15-30 \%$, ferric oxide $5-15 \%$, calcium oxide $1-10 \%$, magnesium oxide $1-10 \% \mathrm{TiO}_{2} 1$ $2 \%$, carbon and its physical properties like porosity, particle size and surface area (Wang et al. 2009; Alinnor and Nwachukwu, 2012).
Many researchers have worked on fly ash waste as adsorbent for removal of pollutants. It is also the substitute for the activated carbon because it is easily available and economically feasible (Mohammed et al., 2014 and Ahiduzzaman and Islam, 2016). Wang and Wu (2006) reported that unburnt carbon present in fly ash is responsible for the adsorption capacity. It is alkaline in nature having $\mathrm{pH}$ greater than 9 . Igwe et al (2013) utilized fly ash for the removal of BOD, TSS, and colour from palm oil mill effluent and studies revealed that percent removal has been increased as dose of adsorbent is increased. $100 \%$ colour removal was achieved in pulp and paper mill effluent at $2.4 \mathrm{~g}$ dose and $\mathrm{pH} 6.8$ as studied by De (2008). Alinnor and Nwachukwu (2012) worked on the removal of phenol from aqueous solution by modified fly ash. So today's concern is development of best utilization techniques of fly ash for treatment of effluents of Pulp and paper mill which is economically sound. The aim of the present study was to find out the characteristics of flyash, its adsorption efficiency and its utilization for the removal of colour from alkali extraction stage wastewater of Pulp and Paper Industry.

\section{MATERIALS AND METHODS}

Effluent collection: The alkali extraction stage $\left(E_{O P}\right)$ wastewater used for study was collected from a pulp and paper mill in Haryana. The mill produces $250 \mathrm{MT} /$ day of writing printing paper by kraft process using bamboo, eucalyptus and hardwood as raw materials. Starting with a kappa number of 20 , the mill produces pulp of 86 to $87 \%$ ISO brightness using CEDD bleaching sequence (where $\mathrm{C}$ is chlorination, $\mathrm{E}$ is alkaline extraction and $D$ is chlorine dioxide). In present study, the alkali extraction stage wastewater is the major contributor for colour to bleach plant effluents. The effluent was characterized after collection for various physico-chemical parameters given in table 1 using standard method of IS and APHA viz. pH (IS 3025 P 11), COD (IS 3025 P 58), Colour (APHA 2120 c), TSS (IS 3025 P 17), TDS (IS 3025 P 16), AOX (ISO 9562) Metals (APHA311B) and stored at $4^{\circ} \mathrm{C}$ for further execution of different experiments.

Fly ash collection: Fly ash waste product of coal thermal power plants was collected from pulp and paper mill in Haryana and analyzed for its properties that make it adsorptive material. The sample was characterized after collection for different parameters given in table 2 using standard method of IS and APHA viz. Moisture, ash, volatile organic carbon fixed carbon (IS1350 P-1) Calorific value (IS1350 P-2) and metals done by APHA 3111B by digesting the sample before analysis. As observed in table 2 physio-chemical analysis of fly ash silica is the major component of fly ash while aluminium and iron were the most abundant cation similar 
trend is reported by (Gupta etal.1985; Sivamani and Leena, 2009).

Further it was stored in tight plastic container for processing the different experiments. The $\mathrm{pH}$ measurements were made using a $\mathrm{pH}$-meter (IS $3025 \mathrm{P} 11$ ) of $2 \%$ slurry. For determination of functional group present in the sample was analysed by using, Fourier Transform Infrared Spectroscopy (FTIR) of Perkin Elmer. A scanning electron microscope (SEM) (model) with Energy dispersive spectroscopy (EDS) was used in present work for the measurement of the morphology and elemental composition of material. Brunauer Emmett Teller was used for determination of surface area porosity of the material.

Adsorption studies: Batch adsorption experiments were carried out in Erlenmeyer flask of 250 $\mathrm{ml}$ capacity by fixing $100 \mathrm{ml}$ constant volume of effluent by adding a pre weight amount of fly ash. Unwashed and washed fly ash was used in present study. During washing, $1 \mathrm{Kg}$ of fly ash was washed with $5 \mathrm{~L}$ distilled water to remove soluble inorganic matter and to eliminate the clogging of pores. Further it was air dried and oven dried at $108{ }^{\circ} \mathrm{C}$ for $24 \mathrm{~h}$, cool at room temperature and finally stored in air tight containers for further use. The effect of dose, agitation rate, $\mathrm{pH}$, temperature and shaking time was studied. The flasks were shaken mechanically for optimized /specific time and then filtered through Whatman number 1 filter paper to remove the suspended matter and check the residual colour.

Percent removal: The percent colour removal (R\%) was calculated by using following equation

$$
R(\%)=\frac{\left(C_{o}-C_{e}\right)}{C_{o}} \times 100
$$

Where, $\mathrm{C}_{0}$ and $\mathrm{C}_{\mathrm{e}}$ was the initial and final concentration of colour in (Pt-Co).

\section{RESULTS AND DISCUSSION}

Colour reduction in alkali extraction stage (E $E_{O P}$ effluent by using unwashed and washed fly ash

Effect of dose of adsorbent: The effect of unwashed and washed fly ash as adsorbent forcolour removal studied at different adsorbent dose $(0.5,1.0,2.0,4.0,5.0$ and $10.0 \mathrm{gm}$ per $100 \mathrm{ml})$ at constant operating conditions (OT: 60 min.; RPM: 100/min; pH: 8.9) showed that the rate of adsorption had increased with increase in adsorbent dose. The results indicated that the colour removal was increased from 18.2 to $83.5 \%$ by using unwashed flyash while using washed flyash, the colour removal was increased from 18.5 to $85.9 \%$ at the same operating conditions (Table 3 ). Slight improvement in colour reduction was observed in case of washed fly ash in comparison to unwashed fly ash. A lot of consumption of water and electricity was involved during the fly ash washing

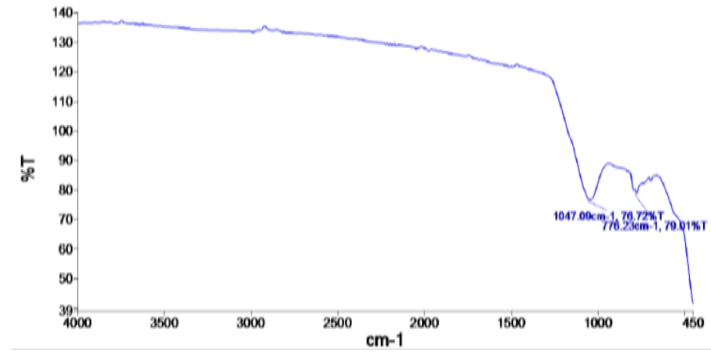

Fig.1. Functional groups analysis of fly ash using FTIR.

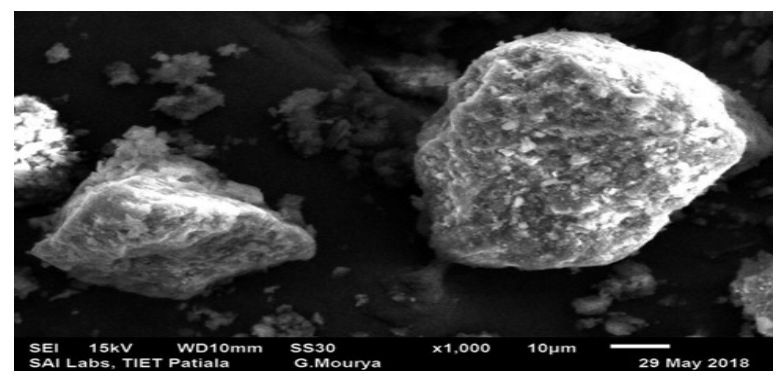

Fig. 2a. SEM of flyash at $1000 x$.

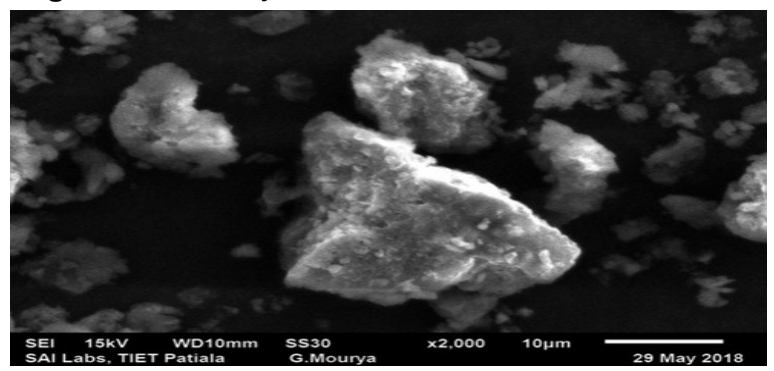

Fig. 2b. SEM of flyash at 2000x.

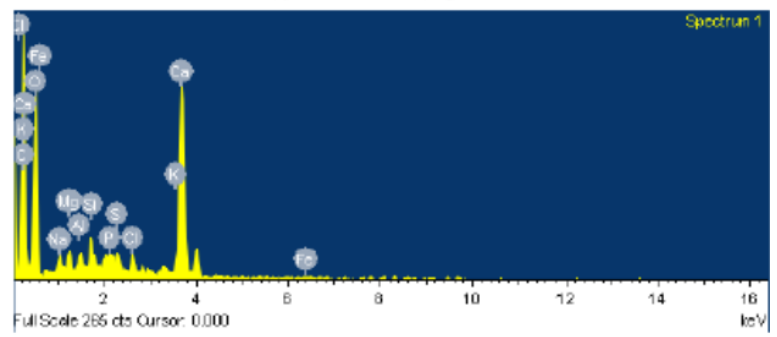

Fig.3. Energy Dispersive Spectroscopy (EDS) spectra of unwashed flyash.

Table 1. Physiochemical characteristics of alkali extraction stage $\left(E_{O P}\right)$ effluents.

\begin{tabular}{lll}
\hline Parameters & Unit & $\begin{array}{l}\text { Alkali extraction stage } \\
\left(E_{\text {OP }}\right)\end{array}$ \\
\hline $\mathrm{pH}$ & -- & 8.72 \\
$\mathrm{COD}$ & $\mathrm{mg} / \mathrm{l}$ & 1264 \\
Colour & $\mathrm{Pt}-\mathrm{co}$ unit & 1675 \\
$\mathrm{TSS}$ & $\mathrm{mg} / \mathrm{l}$ & 166.7 \\
$\mathrm{TDS}$ & $\mathrm{mg} / \mathrm{l}$ & 3472 \\
$\mathrm{AOX}$ & $\mathrm{mg} / \mathrm{l}$ & 70.3 \\
Sodium & $\mathrm{mg} / \mathrm{l}$ & 1096 \\
$\mathrm{Na}$ & & \\
\hline
\end{tabular}

and drying with meager effect on colour reduction, so unwashed fly ash was used for further experiments as far as environmental concerns of water 
Table 2. Physiochemical characteristics and composition of fly ash.

\begin{tabular}{ll}
\hline Properties & $\begin{array}{l}\text { Composition of fly } \\
\text { ash }\end{array}$ \\
\hline $\mathrm{pH}(1 \%$ slurry) & 7.9 \\
$\mathrm{Bulk}$ density $\left(\mathrm{g} / \mathrm{m}^{3}\right)$ & 0.5 \\
Ash \% & 84.1 \\
Volatile organic carbon \% & 4.6 \\
Fixed carbon \% & 10.5 \\
Gross calorific value kcal/kg & 1396 \\
Loss on ignition \% & $17.6 \%$ at $900^{\circ} \mathrm{C}$ \\
Silica as $\mathrm{SiO}_{2} \%$ & 39.4 \\
Aluminum as $\mathrm{Al}_{2} \mathrm{O}_{3} \%$ & 19.7 \\
Iron as $\mathrm{Fe}_{2} \mathrm{O}_{3} \%$ & 5.22 \\
Manganese as $\mathrm{Mn} \%$ & 0.064 \\
Magnesium as $\mathrm{MgO} \%$ & 2.23 \\
Calcium as $\mathrm{CaO} \%$ & 2.16 \\
Potassium as $\mathrm{K}_{2} \mathrm{O} \%$ & 0.41 \\
Sodium as $\mathrm{Na}_{2} \mathrm{O} \%$ & 0.98 \\
\hline
\end{tabular}

and energy are there. Though, the fly ash utilization improved the effluent characteristics in terms of colour reduction but less than the commercial activated carbon.

Results disclosed that 68-96\% phosphate removal in the first $5 \mathrm{~min}$ by fly ash. This is due to fast kinetics and high removal on behalf of precipitation, then a slower and longer removal due to adsorption. It has been established that the percent removal of BOD, TSS, and Colour from palm oil mill effluent increase with an increased the adsorbent dose (Igwe et al.2010). According to Uddin et al., (2017), the removal of dye was increased from 82 to $99 \%$ with an increase in adsorbent dose from 0.1 to $0.8 \mathrm{~g}$. The increase in the dye removal percentage with adsorbent dosages could be attributed to increase in the surface area of adsorbent. Adsorption capacity was decreased from 164 to $25 \mathrm{mg} / \mathrm{g}$ when the adsorbent dose was increased from 0.1 to $0.8 \mathrm{~g}$.

Effect of rotation per minute (RPM): The treatment of EOP by fly ash at different RPM (50, 100 and 150 per min) at constant operating conditions (OT: 60 min.; Adsorbent dose: $10 \mathrm{gm}$; pH: 8.9) indicated the colour the removal efficiency was

Table 3. Effect of adsorbent dose of Unwashed and washed fly ash on colour removal at constant operating conditions (OT: 60 min.; RPM: 100/min; pH: 8.9).

\begin{tabular}{llccc}
\hline Flyash $(\mathbf{g})$ & Volume $(\mathbf{m l})$ & \multicolumn{3}{c}{ \% Colour reduction } \\
\cline { 3 - 5 } & & Unwashed & Washed & \% increase \\
\hline 0.5 & 100 & 18.2 & 18.5 & 0.3 \\
1.0 & 100 & 33.0 & 34.0 & 1.0 \\
2.0 & 100 & 51.5 & 52.2 & 0.7 \\
5.0 & 100 & 67.5 & 69.8 & 2.3 \\
10.0 & 100 & 83.2 & 85.9 & 2.8 \\
\hline
\end{tabular}

Table 4. Effect of RPM on colour removal at constant operating conditions (OT: 60 min.; adsorbent dose: 10 $\mathrm{g} / 100 \mathrm{ml} ; \mathrm{pH}: 8.9)$.

\begin{tabular}{lllccc}
\hline \multirow{2}{*}{ Sl. No. } & \multirow{2}{*}{ Flyash $(\mathbf{g})$} & \multirow{2}{*}{ Volume $(\mathbf{m l})$} & \multicolumn{3}{c}{ Colour reduction at different RPM } \\
\cline { 4 - 6 } & & & $\mathbf{5 0}$ & $\mathbf{1 0 0}$ & $\mathbf{1 5 0}$ \\
\hline 1 & 0.5 & 100 & 17.3 & 18.0 & 17.8 \\
3 & 1.0 & 100 & 29.2 & 30.0 & 29.3 \\
4 & 2.0 & 100 & 50.1 & 51.3 & 48.8 \\
5 & 5.0 & 100 & 66.1 & 66.4 & 66.3 \\
\hline
\end{tabular}

Table 5. Effect of operating time on colour removal at constant operating conditions (RPM: 100/ min; adsorbent dose: $10 \mathrm{~g} / 100 \mathrm{ml}$; $\mathrm{pH}: 8.9)$.

\begin{tabular}{|c|c|c|c|c|c|c|}
\hline \multirow[t]{2}{*}{ SI. No. } & \multirow[t]{2}{*}{ Fly ash (g) } & \multirow[t]{2}{*}{ Volume (ml) } & \multicolumn{4}{|c|}{$\%$ Colour reduction at different times (min) } \\
\hline & & & 30 & 60 & 120 & 240 \\
\hline 1 & 0.5 & 100 & 18.0 & 18.2 & 18.0 & 18.0 \\
\hline 2 & 1.0 & 100 & 30. & 32.3 & 30.1 & 30.0 \\
\hline 3 & 2.0 & 100 & 51.3 & 51.5 & 51.2 & 51.3 \\
\hline 4 & 5.0 & 100 & 66.4 & 67.5 & 66.8 & 66.1 \\
\hline 5 & 10.0 & 100 & 81.0 & 83.2 & 83.1 & 83.1 \\
\hline
\end{tabular}

Table 6. Effect of $\mathrm{pH}$ on colour removal at constant operating conditions (OT: 60 min.; adsorbent dose: 10 g/100 ml; RPM: 100/min).

\begin{tabular}{|c|c|c|c|c|c|c|c|c|c|c|c|}
\hline \multirow{2}{*}{ SI. No. } & \multirow{2}{*}{$\begin{array}{l}\text { Fly ash } \\
\text { (g) }\end{array}$} & \multirow{2}{*}{$\begin{array}{l}\text { Volume } \\
(\mathrm{ml})\end{array}$} & \multicolumn{9}{|c|}{$\%$ colour reduction at different $\mathrm{pH}$} \\
\hline & & & 4 & 5 & 6 & 7 & 8 & 9 & 10 & 11 & 12 \\
\hline 1 & 0.5 & 100 & 18.6 & 18.8 & 18.4 & 18.23 & 18.5 & 24.06 & 18.2 & 18.7 & 19.4 \\
\hline 2 & 1 & 100 & 38.1 & 38.0 & 34.9 & 34.39 & 35.5 & 42.64 & 36.3 & 37.8 & 37.6 \\
\hline 3 & 2 & 100 & 53.6 & 52.5 & 52.2 & 52.11 & 51.1 & 62.70 & 51.1 & 51.8 & 51.6 \\
\hline 4 & 4 & 100 & 60.51 & 60.03 & 57.49 & 57.72 & 57.04 & 79.64 & 68.02 & 56.87 & 59.75 \\
\hline 5 & 5 & 100 & 70.6 & 69.6 & 67.9 & 66.87 & 67.5 & 68.02 & 68.3 & 71.8 & 73.1 \\
\hline 6 & 10 & 100 & 75.82 & 78.65 & 79.63 & 79.91 & 80.63 & 84.19 & 79.53 & 77.60 & 76.39 \\
\hline
\end{tabular}


Malik, A. et al. / J. Appl. \& Nat. Sci. 10 (4): 1318-1324 (2018)

Table 7. Effect of Activated carbon on colour removal at the constant operating contions (100 RPM, OT 60 min. and $\mathrm{pH}$ 9).

\begin{tabular}{llll}
\hline Sl. No & Activated Carbon (FLUKA)(g) & Volume $(\mathbf{m l})$ & \% colour reduction \\
\hline 1 & Control & 100 & \\
2 & 0.05 & 100 & $1.5 \pm 0.0$ \\
3 & 0.1 & 100 & $18.1 \pm 0.0$ \\
4 & 0.5 & 100 & $61.4 \pm 0.1$ \\
5 & 1.0 & 100 & 100 \\
6 & 2.5 & 100 & 100 \\
7 & 5.0 & 100 & 100 \\
\hline
\end{tabular}

Table 8. Elemental analysis of unwashed and chemically modified fly ash.

\begin{tabular}{llllllllllllll}
\hline $\begin{array}{l}\text { Fly } \\
\text { type }\end{array}$ & ash & \multicolumn{11}{c}{ Elemental analysis } \\
\cline { 2 - 15 } & Weight & $\mathbf{C}$ & $\mathbf{O}$ & $\mathbf{N a}$ & $\mathbf{M g}$ & $\mathbf{A l}$ & $\mathbf{S i}$ & $\mathbf{P}$ & $\mathbf{S}$ & $\mathbf{C l}$ & $\mathbf{K}$ & $\mathbf{C a}$ & $\mathbf{F e}$ \\
\hline Unwashed & $(\%)$ & 25.05 & 48.42 & 0.74 & 0.99 & 0.65 & 1.21 & 0.04 & 0.63 & 1.36 & 0.49 & 20.23 & 0.19
\end{tabular}

slightly decreased from $81.22 \%$ to $79.39 \%$ at the agitation speed from 50 to 150 RPM and showed that the no significant improvement was noted with increase in agitation speed beyond the 150 rpm (Table 4).

The percentage of crystal violet adsorption increased up to 15.5-50.0,20.5-60.0 and 25.5-69.7 $\%$ respectively with increasing the agitation speed at 50-900 rpm and different temperatures (310, 320 and $330 \mathrm{~K}$ ), but then gradually approaches a constant value after $900 \mathrm{rpm}$ (Patel and Vashi, 2010). There will be no more reduction in COD, after the equilibrium point has reached. Infact at equilibrium, the rate of adsorption of pollutant onto the activated carbon is almost equal to the rate of desorption (Mohan et al., 2008).

Effect of operating time (OT): The treatment of EOP by fly ash at different operating time (OT) (30, 60,120 and $240 \mathrm{~min}$ ) at constant operating conditions (RPM: 100; Adsorbent dose: $10 \mathrm{gm}$; $\mathrm{pH}$ : 8.9) indicated an increase in removal efficiency from 80.91 to $83.21 \%$ for colour and gradually decreased with an increase in the OT from 60 to 240 min from $27.37 \%$ to $20.57 \%$. On increasing the time above $60 \mathrm{~min}$, no significant improvement in colour reduction was observed. So, 60 min operating time was chosen for the study (Table 5).

It has been explained that the uptake of adsorbate species was rapid in the initial stages of the contact period and became slow near the equilibrium. In between these two stages of the uptake, the rate of adsorption was found to be nearly constant. This result is expected because a large number of surface sites are available for adsorption at the initial stages and after a lapse of time, the remaining surface sites are difficult to occupy because of repulsion between the solute molecules of the solid and bulk phases (Khan et al., 2009). The effect of contact time carried out by using the adsorbent-adsorbate solution with fixed adsorbent dose and initial dye concentration for different time intervals and shaken until equilibrium. Generally the rate of removal of dye increases with an increase in contact time to a certain extended period. Further increase in contact time does not increase the reduction of dye due to deposition of dyes on the available adsorption site on adsorbent material (Ansari and Mosayebzadeh, 2010).

Effect of pH: The treatment of EOP by fly ash at different $\mathrm{pH}(4.0,5.0,6.0,7.0,8.0,9.0,10.0,11.0$ and 12.2) with optimum operating conditions (RPM: 100; Adsorbent dose: $10 \mathrm{gm}$; OT: $60 \mathrm{~min}$ ) indicated that the removal efficiency of colour increased from 75.82 to $84.19 \%$ with the increase in initial pH 5 to 9 of the EOP while the removal efficiency was gradually decreased with an increase in the $\mathrm{pH}$ from 9 to 12 from $84.19 \%$ to $76.39 \%$. Effluent $\mathrm{pH}$ was adjusted by using $0.5 \mathrm{~N} \mathrm{NaOH}$ or $0.5 \mathrm{~N} \mathrm{HCl}$ (Table 6).

It was noted that at the alkaline $\mathrm{pH}$ more than 9 showed the optimum removal efficiency of paper mill effluents. This may be attributed due to increased rate of precipitation of metal ions and colour bearing compounds in alkaline conditions which increased the rate of adsorption as also reported by Varma et al. (2013). It is reported that $\mathrm{pH}$ is increased from 3 to 9 . It appears that silica and alumina, which are chief constituents of fly ash, form metal-hydroxide complexes in solution and the subsequent acidic or basic dissociation of these complexes at the solid-solution interface leads to either positive or negative surface charge (Khan et al., 2009).

Effect of commercial activated carbon: Analysis was performed to draw the comparison of fly ash with commercial activated carbon for treating the paper mill effluent. As shown in Table7 at $1 \mathrm{~g}$ dose of activated carbon, $100 \%$ removal of colour from effluent has occurred whereas on using the same dose of fly ash \% colour removal was just $42.64 \%$ at constant operating conditions (OT: 60 min.; adsorbent dose: $1 \mathrm{~g} / 100 \mathrm{ml} ; \mathrm{pH}$ : 9). Although activated carbon is good for colour removal but it is very costly whereas fly ash is a waste product of industry or easily available at low price. So, industry refuses to use activated carbon for wastewater treatment and shift towards ecofriendly economically feasible adsorbent.

Characterization of fly ash: Surface area, poros- 
ity and functional group present in the adsorptive materialare three most vital properties of any adsorptive material that also characterize the quality of the adsorptive material. The functional groups present on the surface of the fly ash analyzed by the Fourier Transform Infrared Spectroscopy (FTIR) is shown in Fig.1.

The sample of flyash was subjected to FTIR analysis and observed wave numbers $\left(\mathrm{cm}^{-1}\right)$. The characteristics peak around 778 and $796 \mathrm{~cm}^{-1}$ confirmed the presence of quartz (Hlavay et al.,1978; Coates, 1977) present in the sample with Si-O symmetrical stretching vibrations and peak around $1047 \mathrm{~cm}^{-1}$ shows Kaoilinte Si-O stretching of clay minerals Clara and Sugirtha (2016) Ramasamy et al.,2006.

The surface morphology and topography of fly ash was studied at 1000 and 2000X magnification shown in Figs. $2 a$ and $2 b$ shown below. The SEM results of the fly ash clearly showed that the particles look like somewhat spherical large particles. The elemental composition of flyash analyzed by using Energy dispersive spectroscopy (EDS) showed the percent by weight.

The elemental composition of flyash was determined and confirmed by EDS. Elements such as carbon, oxygen sodium, magnesium, aluminium, silica phosphorus, sulphur, chloride, potassium, calcium and iron, carbon shown in Fig. 3 and Table 8.

The Brunauer Emmett Teller (BET) analysis showed that surface area of fly ash used in present study was $8.17 \mathrm{~m}^{2} / \mathrm{g}$, total pore volume of $0.00134\left(\mathrm{~cm}^{3} / \mathrm{g}\right)$ and average pore diameter of $6.552 \mathrm{~nm}$. According to the pore diameter observation, it is mesoporous in nature. Adsorption desorption and Capillary condensation are the characteristic features of mesopores as reported by $\mathrm{Lu}$ et al. (2006); Aworn et al. (2008), Liu et al. (2014); and Clara and Sugirtha (2016).

\section{Conclusion}

The present study concluded that the colour removal efficiency of the Pulp and paper mill increased with increase in the fly ash as adsorbent dose $(0.5$ to $10 \mathrm{gm})$. The optimal operating conditions were unwashed and washed fly ash of $10 \mathrm{gm}$ for the $\mathrm{E}_{\mathrm{OP}}$ effluent of paper mill at the constant operating conditions 100 RPM and operating time of 60 min and $\mathrm{pH} 9$ yielded upto $84.19 \%$ with unwashed fly ash which was found nearer to the $\mathrm{pH}$ of $\mathrm{E}_{\mathrm{OP}}$ effluent. However the removal of colour was observed $85.9 \%$ with washed fly ash at the same operating conditions. The increase in the RPM (50-150) had no significant effect on the removal of colour. It can be said that $100 \mathrm{rpm}$ provided the best balance between maximum colour removal and economical operation. It was established that the activated carbon completely removed the colour using $1 \mathrm{gm}$ adsorbent dose at the constant operating conditions (100 RPM, OT $60 \mathrm{~min}$. and $\mathrm{pH}$ 9) in comparison to fly ash as adsorbent. Mesoporous particles of flyash and elements like carbon play vital role in the process of adsorption. The interesting thing was that the improved solution for disposal of solid waste generated from paper mill such as fly ash may be a good substitute used as the adsorbent for the colour reduction of the paper mill wastewater. Adsorption by fly ash was an environment-friendly process that required short treatment timing, no addition of chemicals and simple operation to improve the quality of the treated wastewater discharge in terms of colour.

\section{REFERENCES}

1. Ahiduzzaman, Md. and Islam, A. K. M. Sadrul, (2016).Preparation of porous bio-char and activated carbon from rice husk by leaching ash and chemical activation. Springerplus. 5(1): 1248.

2. Alinnor, I.J. and Nwachukwu, M.A. (2012) Removal of phenol from aqueous solution onto modified fly ash. International Journal of Research in Chemistry and Environment, 2(2): 124-129.

3. Amuda, O.S. and Ibrahim A.O. (2006). Industrial wastewater treatment using natural material as adsorbent. African Journal of Biotechnology 5:16.

4. Ansari, R. and Mosayebzadeh, Z. (2010). Removal of basic dye methylene blue from aqueous solutions using sawdust and sawdust coated with polypyrrole. J. Iran. Chem. Soc., 7: 339-350.

5. APHA, AWWA, WEF (2012). Spectrophotometric single-wavelength method, Standard Methods for the Examination of Water And Waste Water, (2120 C) (22 Edition)

6. APHA, AWWA, WEF (2012). Direct Air-Acetylene flame method, Standard Methods for the Examination of Water and Waste Water, (3111B) (22 Edition).

7. Aworn, A., Thiravetyan, P., and Nakbanpote, W. (2008). Preparation and characteristics of agricultural waste activated carbon by physical activation having micro-and mesopores. Journal of Analytical and Applied Pyrolysis, 82(2), 279-285.

8. Chakradhar B and Shrivastava Sonia (2004) Colour removal of pulp and paper effluents. Journal of Chemical Technology, 11, 617-621.

9. Clara, J. and Sugiratha P. Kumar (2016). Study of SEM/EDXS and FTIR for flyash to determine the chemical changes of fly ash in marine environment. International journal of scienc and research, 5(7): 1688-1693.

10.Coates J.P., (1977) The IR Analysis of Quartz and Asbestos, Nelioth Offset LTD., Chesham England

11.De, Arnab Kumar (2008) Removal of colour of pulp and paper mill effluent by adsorption on coal fly ash." J. of Industrial Pollution Control, 24 (1): 1-8

12.Devi, R., and Dahiya R. P. (2008). COD and BOD removal from domestic wastewater generated in decentralised sectors. Bioresource Technology, 99(2): 344-349.

13.Dilek, F.B and Bese, S., (2001). Treatment of pulping effluents by using alum and clay-colour removal and sludge characteristics. Water SA, 27(3): 361-366.

14.Dimple, Master, and Mehta, Mehali (2014). Comparative Adsorption of an Acid Dye with Different Activa- 
tion of Fly Ash. International Journal of Engineering Sciences and Research Technology, 3(6): 417-429.

15.Gupta, M. P. and Bhattacharya, P.K. (1985). Studies on colour removal from bleach plant effluent of a kraft pulp mill. Journal of Chemical Technology and Biotechnology. 35(1): 23-32.

16. Hamadi, N. K., Dong Chen, X., Farid, M. M. and Lu, M. G.Q., (2001). Adsorption kinetics for the removal of chromium (VI) from aqueous solution by adsorbents derived from used tyres and sawdust. Chemical Engineering Journal, 84(2): 95-105.

17. Hami, Malik L., M. A. Al-Hashimi, and M. M. Al-Doori (2007) Effect of activated carbon on BOD and COD removal in a dissolved air flotation unit treating refinery wastewater. Desalination, 216(1-3): 116-122.

18.Hlavay J., Jonas K., Elek S., Inezedy J., 1978 Characterization of the particle size and the crystallinity of certain minerals by infrared spectrophotometry and other instrumental method-II Investigation on quartz and feldspar, Clay Minerals, 26:139.

19.Igwe, J.C., Arukwe, U., Anioke, S. N. (2013). Isotherm and kinetic studies of residual oil adsorption from palm oil mill effluent (pome) using boiler fly ash.Environmental Engineering and Management Journal (EEMJ) .12 (3), 417-427.

20.Igwe, J.C., Onyegbado, C.O. and Abia, A.A. (2010) Adsorption isotherm studies of BOD, TSS and colour reduction from palm oil mill effluent (POME) using boiler fly ash. Eclética Química, 35(3): 195-208.

21.Karrasch B., Parra, O., Cid, H., Mehrenset, M., Pacheco, P., Urrutia, R., Valdovinosal, C. and Zaror, C., (2006). Effects of pulp and paper mill effluents on the microplankton and microbial self-purification capabilities of the Biobio River, Chile. Science of the Total Environment, 359(1): 194-208.

22.Khan, T.A., Ali, I., Singh, V.V. and Sharma, S. (2009). Utilization of fly ash as lowcost adsorbent for the removal of methylene blue, malachite green and rhodamine B dyes from textile wastewater. J. Environ. Protect Sci., 3: 11-22.

23.Lacorte S., Latorre A., Barcelo D., Rigol A., Malmqvist A. and Welander T. (2003). Organic compounds in paper-millprocess waters and effluents. Trends in Analytical Chemistry, 22(10), 725-737.

24.Liu, J., Tang, K., Qiu, Q., Pan, D., Lei, Z., and Xing, F. (2014). Experimental investigation on pore structure characterization of concrete exposed to water and chlorides. Materials, 7(9), 6646-6659.

25.Lu, C., Chung, Y. L., and Chang, K. F. (2006). Adsorption thermodynamic and kinetic studies of trihalomethanes on multiwalled carbon nanotubes. Journal of hazardous materials, 138(2), 304-310.

26.Malaviya, P. and Rathore, V.S. (2007) Seasonal variations in different physico-chemical parameters of the effluents of Century Pulp and Paper Mill, Lal Kuan, Uttarakhand. Journal of environmental biology, 28(2): 219-224.

27.Medhi, U.J., Talukdar, A.K. and Deka, S. (2011)
Impact of paper mill effluent on growth and development of certain agricultural crops. 32(2):185-188

28.Mohammed M.A., Shitu A. and Ibrahim A.(2014). Removal of Methylene Blue Using Low Cost Adsorbent: A Review. Research Journal of Chemical Sciences 4(1): 91-102,

29.Mohan, D., P.S. Kunwar and K.S. Vinod. 2008. Wastewater treatment using low cost activated carbons derived from agricultural byproducts-A case study. J. Hazard. Mat., 152: 1045-1053

30.Patel, H. and Vashi R.T. (2010) Adsorption of Crystal Violet Dye onto Tamarind Seed Powder.E-Journal of Chemistry, 7(3): 975-984

31.Pokhrel, D. and Viraraghavan, T. (2004). Treatment of pulp and paper mill wastewater-a review. Science of the total environment 333.1: 37-58.

32.Popuri Ashok Kumar, Mandapati, Ramesh Naidu, PagalaBangaraiahandGuttikonda, Prashanti, (2016). Colour Removal from Dye Wastewater using Adsorption. International Journal of Pharmaceutical Sciences Review and Research 39.1:115-118.

33.Renge, V.C. and Khedkar, S.V. (2012) Removal of heavy metals from wastewater using low cost adsorbents: a review. Scientific Reviews and Chemical Communications 2(4)

34.Shivnarayan Singh, (2015) Study of Waste Water Effluent Characteristics Generated from Paper Industries. Journal of Basic and Applied Engineering Research 2(17): 1505-1509.

35.Sivamani, S. and Leena, G.B. (2009). Removal of Dyes from Wastewater using Adsorption-A Review. Int. J. Biosci. Technol 2(4): 47-51.

36. Thapliyal, B.P and Tyagi, S. (2015). Water pitch analysis- An innovative approach towards water conservation in pulp and paper industry. IPPTA, 27(3):59-66

37.Uddin, M. T., Rahman, Md. A., Rukanuzzaman, Md. and Islam, Md. Akhtarul (2017). A potential low cost adsorbent for the removal of cationic dyes from aqueous solutions. Appl .Water Sci., 7:2831-2842

38. Uğurlu M, Karaoğlu MH and Kula I (2006). Experimental Investigation of Chemical Oxygen Demand, Lignin and Phenol Removal from Paper Mill Effluents Using Three-Phase Three-Dimensional Electrode Reactor. Polish Journal of Environmental Studies, 15.4

39.Varma G, Singh, R.K. and Sahu, V. (2013). A comparative study on the removal of heavy metals by adsorption using fly ash and sludge: a review. International Journal of Application or Innovation in Engineering and Management 2.7 45-56.

40.WANG, ChunfengLI, Jiansheng, SUN, Xia, WANG, Lianjun, SUN, Xiuyun (2009). Evaluation of zeolites synthesized from fly ash as potential adsorbents for wastewater containing heavy metals." Journal of Environmental Sciences 21.1: 127-136.

41.Wang, S. and Wu, H. (2006). Environmental-benign utilisation of fly ash as low-cost adsorbents. Journal of Hazardous Materials, 136(3), 482-501. 